\section{P125 NON-INVASIVE ASSESSMENT OF VENTILATION DISTRIBUTION IN INFANTS USING ELECTRICAL IMPEDANCE TOMOGRAPHY (EIT)}

doi:10.1136/thx.2010.150987.26

P A Shah, H Shannon, A-F Hoo, D Ahmed, J Chudleigh, J Stocks. The UCL Institute of Child Health, London, UK

Background Early detection of lung disease in conditions such as cystic fibrosis (CF) is vital to maximise lung health but lung function tests (LFT) during the 1st year of life are limited to a few specialised centres. Electrical Impedance Tomography (EIT) provides a novel non-invasive technique for measuring breathing patterns and regional ventilation but its use has generally been restricted to anaesthetised or ventilated subjects in intensive care. ${ }^{12}$

Aim To assess the feasibility and potential usefulness of EIT for monitoring changes in breathing pattern and ventilation distribution in spontaneously breathing sleeping infants.

Methods Simultaneous recordings of EIT (Goe-MF II EIT system) and changes in tidal volume using a pneumotachograph (PNT) were made in the supine position in infants undergoing standard LFT under chloral sedation, before and after application of face mask and PNT, and during tidal breathing (TB) vs passive lung inflations (PLI) to $30 \mathrm{cmH}_{2} \mathrm{O}$.

Results To date, paired data have been obtained from $9 / 10$ infants in whom measurements were attempted (aged 3-12 months: five $=\mathrm{CF}$ and four=healthy controls, one technical failure of EIT). Application of the face mask resulted in a mean (range) 27 (12-39)\% increase in impedance. Compared with TB, PNT volume increased by mean

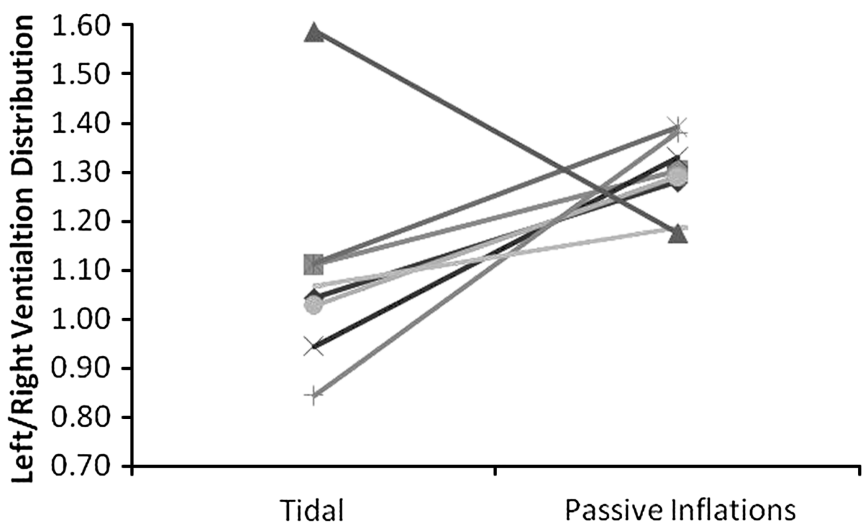

Breathing Pattern

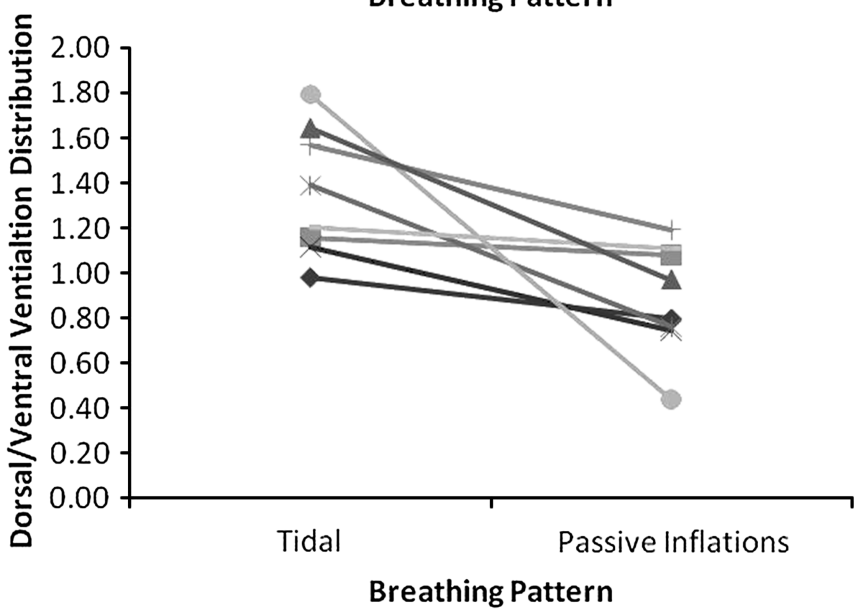

Abstract P125 Figure 1 Change in ventilation distribution in sleeping, supine during different breathing patterns.
(SD) 127 (20)\% during PLI, which was accompanied by a $152(22) \%$ increase in impedance. During TB, ventilation was relatively evenly distributed between left (L) and right (R) lung, mean (SD) L/R:1.09 (0.22) and, as in adults, was preferentially distributed to the dependent (dorsal) lung (dorsal/ventral (D/V):1.36 (0.29)). During PLI, there was a significant shift in ventilation distribution to the left and ventral portions of the lung (mean (95\% CI) L/R:1.29 (1.24; 1.35); D/V:0.89 (0.71;1.06)) (Abstract P125 Figure 1). Data collection is continuing.

Conclusions These results suggest that EIT maybe a useful noninvasive method of monitoring changes in breathing pattern and ventilation distribution in spontaneously breathing infants. Despite suggestions that distribution of ventilation differs in infants, the preferential distribution to the dependent lung during tidal breathing mimics that seen in adults. Improvements in software and equipment will be required prior to routine applications.

Funding This work was supported by the British Lung Foundation, Cystic Fibrosis Trust and GOSH Special Trustees.

\section{REFERENCES}

1. Pillow JJ, Frerichs I, Stocks J. Lungfunction tests in neonates and infants with chronic lung disease: global andregional ventilation inhomogeneity. Pediatr Pulmonol 2006:41:105-21.

2. Frerichs I, Schiffmann $\mathrm{H}$, Oehler $\mathrm{R}$, et al. Distribution of lung ventilation in spontaneously breathing neonates lying indifferent body positions. Intensive Care Med 2003;29:787-94.

\section{P126 THE INFLUENCE OF BREATHING PATTERN ON SPECIFIC AIRWAYS RESISTANCE}

doi:10.1136/thx.2010.150987.27

\section{J C Kirkby, S Sonnappa, J Stocks. UCL, Institute of Child Health, London, UK}

Introduction Plethysmographic Specific Airways Resistance (sRaw) is measured during tidal breathing from the relationship between simultaneous measurements of airflow and change of plethysmographic pressure without need for airway occlusion. ${ }^{1}$ sRaw has been shown to be useful for discriminating lung disease in young children. It has previously been shown that breathing frequency (BF) can have a marked impact on measured values on sRaw, ${ }^{2}$ and recent recommendations have suggested $\mathrm{BF}$ should be maintained at 30-45 bpm. ${ }^{3}$ However, we hypothesise that the true impact of breathing pattern may relate more to pattern of breathing and flows attained than breathing frequency per se.

Aim To determine the influence of flow and breathing frequency on specific effective airways resistance (sReff) measurements.

Methods 12 healthy adults (age 17-56 year) performed repeated measures of sReff in the plethysmographic body box (V5.01, Cardinal Health) at either $30 \mathrm{bpm}$ or $60 \mathrm{bpm}$ at low flows (ie, quiet, natural breathing) or high flows (ie, forced breathing) in a random order. Paired t-tests were used to determine the impact of flow and BF on sReff.

Results There was a significant increase in sReff (mean difference: $0.3 \mathrm{kPa} \cdot \mathrm{s}$ (95\% CI of the difference: 0.2 to 0.4$) \mathrm{p}<0.0001$ ) when flows were doubled from approximately $\pm 1 \mathrm{l} / \mathrm{s}$ to $\sim \pm 2 \mathrm{l} / \mathrm{s}$, while maintaining a constant BF. By contrast, when BF was doubled while maintaining a constant flow there was no significant change in sReff (mean difference: $0.06 \mathrm{kPa} \cdot \mathrm{s}$ (95\%CI of difference: 0 to 0.1$), p=0.21$ ) (Abstract P126 Figure 1). 